\title{
Las Mujeres Científicas en la España Actual. Representaciones Sociales
}

\author{
María Teresa GARCía NiETO \\ Universidad Complutense de Madrid \\ nieto@ccinf.ucm.es \\ Mónica VIÑARÁs ABAD \\ Universidad CEU San Pablo \\ monica.vinarasabad@ceu.es
}

\begin{abstract}
Resumen:
El estudio que presentamos forma parte del Proyecto de Investigación para el Fomento de la Igualdad de Género en la información Científica (IFIGIC), financiado por el Instituto de la Mujer, del Ministerio de Sanidad, Política Social e Igualdad. En él pretendemos poner en evidencia la falta de notoriedad de las mujeres científicas en la realidad social española actual, desvelando, además, las diferentes imágenes y representaciones sociales que las mujeres y los hombres tienen hacia este colectivo.

Para ello, hemos realizado un estudio, cualitativo y exploratorio, desarrollando tres grupos de discusión; uno de ellos formado exclusivamente por mujeres, otro constituido por hombres y un tercero mixto, formado por mujeres y hombres.

Los resultados no pueden ser más esclarecedores. El conocimiento social, acerca de las personas dedicadas a la investigación científica en nuestro país, es muy escaso y poco significativo. Las mujeres y los hombres no disciernen el carácter científico de las mujeres y las perciben, simplemente, como a otras mujeres profesionales. Asimismo, las mujeres y los hombres tienen imágenes diferentes de las mujeres profesionales y estas representaciones responden, de forma peculiar, a patrones estereotipados. Esta grave falta de notoriedad pública de las mujeres científicas españolas, además de la estereotipia de sus representaciones sociales, favorecen ciertos efectos perniciosos y no deseados: el inmovilismo social y la permanencia de una situación desequilibrada y desigual, manifiestamente propicia para los hombres. El proyecto IFIGIC tiene el propósito de cambiar esta no querida realidad, propiciando el fomento de la igualdad de género en la información científica, facilitando, de manera progresiva, el proceso de evolución hacia la igualdad de género en el escenario científico español.
\end{abstract}

Palabras clave: mujeres científicas; representación social; estereotipos; medios de comunicación; género.

\section{The Scientific Women in the Current Spain. Social representations.}

\begin{abstract}
:
This study is a part of the Project of Investigation for the Promotion of the Gender Equality in the Scientific information (IFIGIC), financed by the Institute of Women, of the Ministry of Health, Social Services and Equality. We here try to highlight the lack of recognition of the scientific women in the actual society in Spain, revealing, in addition, the different images and social representations that the women and the men have towards this group.

With this aim in mind, we have performed a study, qualitatively and exploratory, developing three focus groups; one of them formed exclusively by women, other one being constituted by men only, and a mixed third group formed by women and men.

The results of the study cannot be more enlightening. The social knowledge, about the persons working scientific investigation in Spain, is very scanty and slightly significant. Women and men do not discern
\end{abstract}


the scientific character of the women and perceive them, simply, as other professional women. Furthermore, women and men have different images from the professional women and these representations correspond, in a peculiar form, to stereotyped schemes. This serious lack of public recognition of the Spanish scientific women and their stereotyped social representation are favoring certain pernicious and not wished effects: the social immobility and the permanency of an unbalanced and unequal situation, manifestly advantageous for men.

The project IFIGIC has the intention of changing this unwanted reality, enhancing the promotion of the gender equality in the scientific information, and facilitating, in a progressive way, the process of evolution towards the gender equality in the scientific Spanish scene.

Key Words: women scientific; social representation; stereotypes; media; gender.

\section{Referencia normalizada:}

García Nieto, M.T. y Viñarás Abad, M. (2014): Las mujeres científicas en la España actual. Representaciones sociales. Historia y Comunicación Social. Vol. 19. Núm. Especial Enero. Págs. 623-639.

Sumario: 1. Introducción. 2. Ciencia, mujeres y representaciones sociales. 2.1. Representaciones sociales y ciencia. 2.2. La influencia de los medios en las representaciones sociales. 2.3. Realidades y estereotipos de las mujeres científicas. 3. Un análisis cualitativo: la representación social de las científicas en España. 3.1. Un desinterés manifiesto. 3.2. Representaciones sociales distintas y conservadoras. 3.3. La representación social de las personas de la ciencia en España. 3.4. La representación social de las científicas en España. 4. Conclusiones. 5. Referencias bibliográficas.

\section{Introducción}

La aportación epistemológica, que presentamos en este artículo, es una parte del trabajo realizado en el Proyecto de Investigación para el Fomento de la Igualdad de Género en la Información Científica. Su objetivo es conocer, desde un enfoque cualitativo y de forma exploratoria, el grado de notoriedad y las diferentes imágenes que las mujeres y los hombres tienen de las científicas en nuestro país.

Para nuestro propósito, realizamos tres grupos de discusión de titulados universitarios: uno de mujeres, otro de hombres y un tercero mixto, a modo de grupo de control. Además, tuvimos en cuenta una circunstancia previa: que las personas con estudios superiores, dado el carácter científico de su formación académica, deberían tener, a priori, más familiaridad y conocimiento de los temas científicos que el resto de la población. A continuación, presentamos los resultados obtenidos, reflejo de las representaciones sociales sobre las mujeres científicas en España, que constatan su escaso protagonismo.

\section{Ciencia, mujeres y representaciones sociales}

El proceso de la percepción humana, cómo es harto sabido, está condicionado por los estímulos a los que nos exponemos y recibimos. Además, nuestra experiencia previa, nuestras creencias, conocimientos y actitudes, también condicionan este 
proceso selectivo de atención e interpretación del mundo circundante. Los actuales postulados de la Psicología y la Sociología afirman que el individuo presta especial atención a todo aquello que le es familiar, a lo que le resulta interesante o le afecta directamente; por lo cual, probablemente, sólo aquello que ya forma parte de su experiencia de vida tiene mayor probabilidad de recibir su atención. A su vez, los medios de comunicación nos acercan el entorno más lejano, y a partir de sus mensajes, construimos la realidad, especialmente en aquellos asuntos alejados de nuestra vida cotidiana. Así, la información de los medios es parte de nuestra experiencia, influye en nuestras creencias, y condiciona la percepción de los estímulos a los que nos exponemos. En nuestro estudio, partimos de la excepcional importancia que tienen los medios de comunicación, al difundir los mensajes sobre ciencia, en la formación, el cambio y el refuerzo de los conocimientos y las creencias de las personas, como individuos, y de sus representaciones sociales como grupo,

\subsection{Representaciones sociales y ciencia}

Desde la perspectiva del grupo, y por lo tanto, de los individuos que lo forman, es necesario organizar la información, de una determinada manera, de forma que simplifique el proceso de percepción y de interpretación. Desde la Psicología Social, Hogg (2010: 176) defiende que "las representaciones sociales transforman lo poco familiar y complejo, en familiar y simple; y así brindan un marco de trabajo para interpretar nuestras nuevas experiencias". En este sentido, las actitudes del individuo están socialmente construidas y reflejan los grupos sociales a los que éste pertenece.

El concepto de representación social recoge la idea del conocimiento común y compartido, que supone la opinión del grupo. Moscovici (1984) desarrolla el concepto de «representaciones sociales», que va a permitir destacar los factores sociales de la percepción y, con ello, subrayar la importancia que los grupos y sus «normas» tienen sobre la representación de la realidad social. Este autor, recoge el concepto de "representaciones colectivas" de la sociología clásica de Émile Durkheim (2000). La importancia del concepto de representación social radica en que integra, con enfoque heurístico, por un lado, las nociones propias de la tradición psicológica, como imágenes, percepciones, actitudes y procesamiento de la información y, por otro, conecta con concepciones sociológicas como normas, valores, culturas o ideologías.

... podemos considerar que, a pesar de que una Representación Social comprende una amplia gama de fenómenos, puede entenderse como un sistema de referencia que nos permite dar significado a los hechos. Es decir, nos permiten ver ciertos acontecimientos y establecer aserciones, pero también suponen una manera de clasificar fenómenos, imágenes, etc. (Lacolla 2005: 3).

Se trata así de un concepto que suma, al proceso interno del individuo, la creencia social sobre un tema, como parte de su cultura, sus valores y sus ideologías. No se trata sólo de lo que el individuo piense de manera individual, sino que la representación social condiciona asimismo, desde el grupo, la percepción y la creencia individual y, de ese modo, condiciona también las creencias del propio grupo. Moscovici 
sostiene que el individuo construye sus creencias socialmente, o sea, que sus ideas y opiniones son moldeadas por lo que otras personas creen y dicen.

Respecto al objeto de estudio que nos ocupa, la ciencia, y los científicos y científicas, nos encontramos con un referente complejo, técnico y especializado, alejado de la cotidianeidad del individuo, y que por tanto, encaja con la necesidad de representación social, para poder dar un significado y entender algo que nos es ajeno. La percepción de la ciencia y sus agentes, exige una interpretación desde el emisor (el científico) al receptor, el individuo y el grupo, a través de la adaptación del código compartido para que sea fácilmente interpretado. Aquí los medios de comunicación juegan un papel fundamental, puesto que son ellos los que hacen esa adaptación como intermediarios de la información científica, el científico, el individuo y el grupo, en la mayoría de las ocasiones.

En este sentido, la Fundación Española para la Ciencia y la Tecnología (FECYT), reconoce que "tenemos otro grave problema planteado (...): la existencia de una comunicación y divulgación de las ciencias realmente deficientes" $(2011,12)$; tal es así, que en 2009 manifiesta reconocer el declive en la cobertura periodística de las ciencias.

Porque hoy seguramente ya no es necesario abogar por más divulgación de las ciencias - a pesar de que en muchos medios, sobre todo en prensa, hayan desaparecido secciones y especialistas en información científica - sino por una mejor contextualización del discurso científico que permita una mayor comprensión pública.

Es decir, es necesario realizar un esfuerzo para conseguir una mayor comprensión pública, de los contenidos científicos, que influya directamente en las representaciones sociales sobre la ciencia, y consecuentemente, sobre las mujeres científicas.

\subsection{La influencia de los medios en las representaciones sociales}

Las más recientes investigaciones sobre la percepción de la ciencia, recogen que el interés de la población española en temas científicos, es similar a la media europea, un 5,7 en una escala de 0 a 10, próximo al de los temas internacionales, un 5,6, y por encima del interés por los asuntos políticos, un 4,5. Pese a todo, este interés queda por debajo del manifestado para otras cuestiones, como la salud, un 7,9; el medio ambiente y la economía, un 6,7. No obstante, el interés por la ciencia, en los dos últimos años, ha crecido un 19\%, situándose en un 15,5\% en 2012 (Fundación BBVA, 2012, y FECYT, 2012). Sin embargo, Torres (2005), tras analizar datos de trece encuestas nacionales realizadas en los últimos años por diferentes organismos (1982-2004) sobre la percepción de la ciencia, afirma que en España no hay una mayoritaria valoración positiva de la ciencia y la tecnología, y que tampoco la alfabetización científica influye notablemente. En cualquier caso, no destaca un especial interés, o así lo recogen las encuestas.

Los medios de comunicación son, en consecuencia, uno de los factores determinantes de la creación y formación de las representaciones sociales, como ya recogía 
Moscovici $(1979,1984)$, además de insistir en la fuerte influencia que ejercen en la construcción de un universo común y consensuado. Torres (2005: 40) habla directamente de las cuatro esquinas sobre las que se soportan las interacciones de un sistema de comunicación: los propios científicos y tecnólogos, los políticos y gestores de la tecnociencia, los prescriptores de la opinión pública a través de los medios de comunicación de masas y, finalmente, la audiencia. "Los medios de comunicación son responsables además, de facilitar ese entendimiento entre agentes en ocasiones muy alejados y distantes, porque no comparten un beneficio común directo, o por lo menos así se percibe".

Desde una perspectiva psicológico social, de la formación de las imágenes y creencias del individuo, "los ciudadanos y las ciudadanas construyen, en una gran medida, sus imágenes mentales como conjuntos de creencias forjadas a partir de las informaciones de los medios de comunicación" (García Nieto, 2013: 2). Los mensajes periodísticos son, por tanto, un importante estímulo que influye en la representación social como parte fundamental de nuestro entorno. La cobertura de los medios en temas de ciencia determina nuestra propia percepción de la misma, así como el contenido de esta información, determina la imagen social de los científicos y las científicas.

El citado estudio del FECYT (2011) reconoce, sin embargo, una beneficiosa evolución en la relación entre periodistas y científicos. Ya ha pasado aquella etapa en la cual los científicos no reconocían sus investigaciones en las informaciones periodísticas, pues pensaban que el periodista distorsionaba sus mensajes; además sus colegas consideraban presuntuosas tales intervenciones mediáticas. Hoy día, los científicos reconocen el importante papel del periodista en la difusión y divulgación de la ciencia, tarea necesaria para crear una cultura científica.

La circulación de información científica en la sociedad implica una serie de procesos mediante los cuales el conocimiento, los códigos y valores de la ciencia y la tecnología se transmiten a la sociedad, se incorporan al acervo cultural y devienen en cierto uso cotidiano de la ciencia construyendo representaciones sociales diversas sobre ésta, no necesariamente articuladas entre sí, aunque tampoco del todo desarticuladas, ya que tienen como fondo común las prácticas culturales (Domínguez-Gutiérrez, 2005: 5).

A pesar de que la relación entre periodistas y científicos parece evolucionar y presenta mejoras, según este informe, los primeros resultados de nuestra investigación demuestran la ausencia de las mujeres científicas en los medios de comunicación, lo cual constituye un impedimento para su desarrollo y su crecimiento social y profesional.

El análisis de contenido de la prensa escrita, realizado en la primera fase de la investigación, descubre la existencia de una evidente desigualdad en el tratamiento informativo, relativo a los hombres y a las mujeres de la ciencia en España, que prima $\mathrm{y}$ favorece a los hombres y oculta y ensombrece a las mujeres. Esta desigualdad no sólo queda en evidencia en el estudio cuantitativo de los mensajes periodísticos, sino también en el análisis cualitativo. Éste revela un preocupante y distinto tratamiento informativo; muy benévolo con los protagonistas masculinos de la ciencia y absolu- 
tamente neutral con las mujeres científicas, al omitir cualquier rasgo favorable hacia ellas (García Nieto, 2013).

En internet, los datos son aún más desesperanzadores: las mujeres son prácticamente invisibles en los mensajes científicos publicados en la red (ibid: 791). La falta de notoriedad pública de las mujeres científicas españolas y la estereotipia de sus representaciones sociales, contribuyen al inmovilismo social y a la perpetuidad de una situación desigual y desequilibrada, claramente favorable para los hombres.

\subsection{Realidades y estereotipos de las mujeres científicas}

La Comisión Europea publicó el pasado 5 de abril de 2013 las cifras sobre la participación de las mujeres en Investigación e Innovación en el Informe She-Figures. El estudio recoge datos del periodo 2002 y 2009, refiriéndose a la presencia de mujeres en el sector de enseñanza superior, las administraciones públicas y el sector empresarial:

El número de mujeres creció anualmente en un 5,1\%, pero aun así, las mujeres investigadoras siguen teniendo dificultades para llegar a los cargos con poder de decisión, de manera que, por término medio, los consejos científicos y de administración de toda la UE cuentan solo con una mujer por cada dos hombres.

El año anterior, la Comisión Europea, ponía en marcha una campaña para promover la incorporación de mujeres jóvenes a la investigación científica, Science: It's a girl thing!, ante la evidencia de que las mujeres todavía tienen que luchar por su reconocimiento en la vida científica e investigadora, a pesar de la existencia de un mayor número de mujeres que de hombres en la educación universitaria.

Tal y como ocurre en el resto de la Unión Europea, las mujeres también constituyen una minoría en la profesión científica en España, alcanzando sólo el 37,50\% del total del personal investigador en la Universidad pública en 2009. Según revela el informe de la Unidad de Mujeres y Ciencia del Ministerio de Economía y Competitividad (UMYC), en 2009, el promedio de las mujeres en el colectivo de investigadores en la Educación Superior era aún del 37,5\% y del 43,57\% en todo el sector público español (Científicas en Cifras, UMYC, 2011). Este mismo organismo publica en su Libro Blanco de la Situación de las Mujeres y la Ciencia, la evolución de las mujeres en la ciencia y su carrera profesional en España. 
Gráfico 1. Evolución de la proporción de mujeres y hombres en la carrera investigadora, estudiantes y personal investigador (1997-2007). En Cientificas en Cifras. Estadísticas e indicadores de la (des)igualdad de género en la formación y profesión científica.

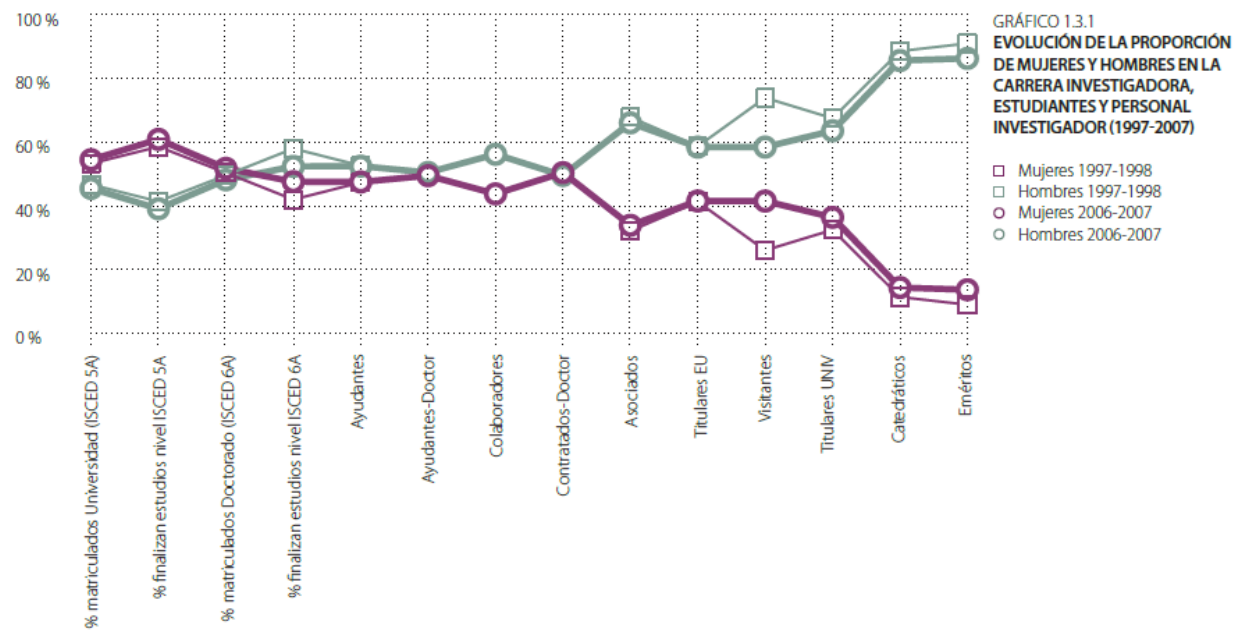

A lo largo de una década, entre 1997 y 2007, se ha producido un descenso en el Índice de techo de cristal (www.mujeresyciencia.com) en la Universidad pública española. Ello significa que, a pesar de las dificultades que las mujeres encuentran en su promoción profesional en la Universidad, la situación es ligeramente más favorable y optimista de cara al futuro por el efecto generacional. Sin embargo, el índice se sitúa en 2.34, por encima de la media en la UE (1.8 en 2007) y existen diferencias importantes según el área de conocimiento, cuyos valores oscilan de 2 en las Humanidades a 3.06 en las Ciencias Médicas (Científicas en España en cifras en 2011).

Gráfico 2. Índice de techo de cristal, 1995-1996/2008-2009. En Científicas en Cifras. Estadísticas e indicadores de la (des)igualdad de género en la formación y profesión científica.

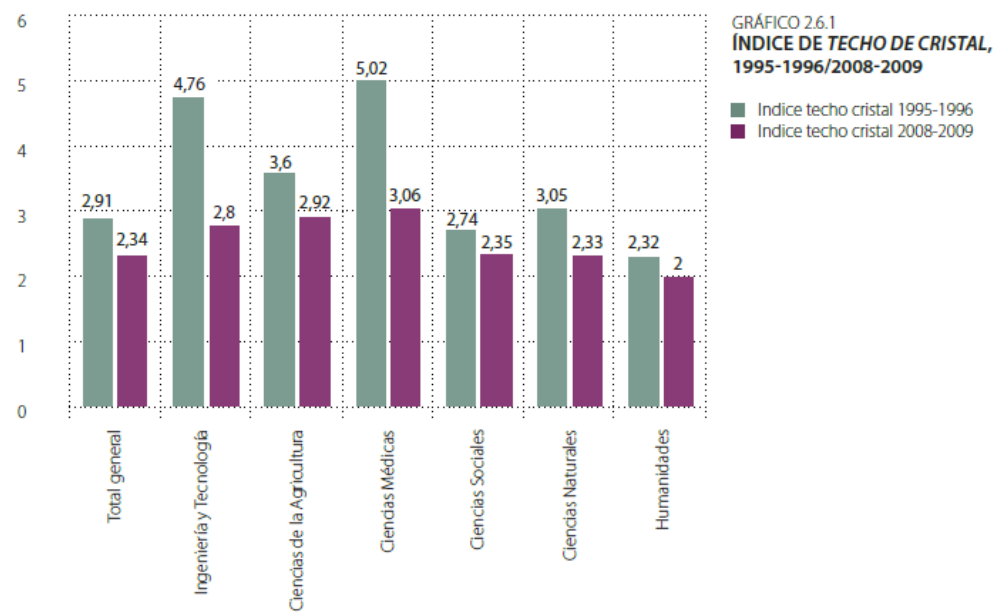


Algunos autores aseguran que la elección de los estudios superiores está condicionada por los estereotipos; así las profesiones de carácter técnico son elegidas preferentemente por los hombres, mientras que las de carácter más social o humanístico están más destinadas a las mujeres (Candela \& otros, 2009: 28). Los datos demuestran estas afirmaciones.

Tabla 1. Porcentaje de doctores por campo de doctorado y sexo en 2009.

Unidades: porcentaje.

\begin{tabular}{|l|r|r|r|}
\hline & Total & Hombres & Mujeres \\
\hline Total & 100,00 & 55,45 & 44,55 \\
\hline Ciencias Naturales & 33,27 & 18,91 & 14,36 \\
\hline Ingeniería y Tecnología & 8,01 & 5,70 & 2,31 \\
\hline Ciencias Médicas & 20,89 & 10,35 & 10,54 \\
\hline Ciencias de la Agricultura & 2,98 & 1,59 & 1,40 \\
\hline Ciencias Sociales & 20,14 & 10,76 & 9,38 \\
\hline Humanidades & 14,70 & 8,14 & 6,56 \\
\hline
\end{tabular}

Fuente: Instituto Nacional de Estadística

Tabla 2. Porcentaje de titulados universitarios por campo y sexo en 2011.

Unidades: porcentaje.

\begin{tabular}{|l|r|r|r|}
\hline & Total & Hombres & Mujeres \\
\hline Total & 100,00 & 40 & 60 \\
\hline Ciencias Experimentales & 5,3 & 37 & 63 \\
\hline Ciencias de la Salud & 12,4 & 24 & 76 \\
\hline Ciencias Sociales y Jurídicas & 55,4 & 33,1 & 66,9 \\
\hline Humanidades & 6,8 & 35,6 & 64,4 \\
\hline Técnicas & 20,1 & 71 & 29 \\
\hline
\end{tabular}

Fuente: Instituto Nacional de Estadística

De las titulaciones técnicas, el 32\% corresponden a estudios de Arquitectura e Ingeniería.

Tabla 3. Porcentaje de hombres y mujeres titulados en Arquitectura e Ingenierías.

Unidades: porcentaje.

\begin{tabular}{|l|rrrr|}
\hline & Total & Hombres & Mujeres \\
\hline $\begin{array}{l}\text { Arquitectura e } \\
\text { Ingenierías }\end{array}$ & 8,5 & 68 & 32 \\
\hline
\end{tabular}

Fuente: Instituto Nacional de Estadística 
La percepción de esta realidad, sin embargo, queda deformada por los estereotipos. Los estereotipos son "imágenes mentales" que se utilizan como una forma de economizar (Lippman, 1922. Pág. 87). Los estereotipos son imágenes sesgadas de la realidad. Los estereotipos representan la realidad, compleja y diversa, por medio de ciertos rasgos generalizados en exceso. Son imágenes simplificadas, comúnmente aceptadas, atribuidas a un colectivo de forma general. Seiter (1986. Pág. 19), desde los presupuestos de la comunicación de masas, define los estereotipos como "representaciones falsas e inmorales de la realidad". Añade así la nota negativa o peyorativa que han adquirido los estereotipos por su reducción perjudicial de la realidad.

El Manual de Género en la Investigación, promovido por la Comisión Europea, entiende el género como la "construcción social de mujeres y hombres, de feminidad y masculinidad, que varía en el tiempo y el espacio y entre las culturas" (Comisión Europea, 2011). Kahn y Gordon (1997: 61) sostienen que los patrones de socialización, basados en las percepciones generalizadas de lo que podrían considerarse comportamientos apropiados de acuerdo con el género, son responsables del desarrollo de los estereotipos de género que imperan en la actualidad. Es decir, una norma social genera estereotipos que, a su vez, alimentan esas normas.

En este orden de cosas, el proyecto TWIST (Towards Women in Science and Technology) cuestiona los prejuicios sociales que provocan esta desigualdad entre los sexos, mediante una serie de programas y actividades celebrados en centros científicos y museos de toda Europa. En el proyecto, apoyado por la Comisión Europea, participan once socios coordinados por el centro científico Experimentarium de Copenhague (Dinamarca).

Los patrones estereotipados, acerca de la idoneidad de los campos científicos para uno u otro sexo, forman parte de la construcción de las expectativas formativas y profesionales de las niñas y de las adolescentes, y siguen afectando a las jóvenes a la hora de optar por las distintas vías que el sistema educativo ofrece, consolidándose estos estereotipos especialmente en la formación profesional (FECYT, 2007). Un estudio realizado entre alumnos de formación profesional (Porto \& otros, 2012) revelaba la necesidad de corregir estos estereotipos desde la escuela, y sobre todo:

Es también fundamental hacer visible y reforzar la imagen de la mujer en el ámbito tecnológico para, de este modo, fomentar una actitud más positiva hacia la tecnología por parte de las mujeres, así como una mejor integración las mismas a los ámbitos técnicos tanto educativos como profesionales.

La escasa presencia de mujeres en la ciencia y la tecnología no tiene que ver con su capacidad, intereses y habilidades técnicas, sino que es consecuencia de factores externos, tales como las barreras organizativas de las instituciones académicas, los efectos diferenciales de las demandas del trabajo y de la familia, la infrarepresentación de las mujeres en posiciones con capacidad de decisión y de liderazgo académico y los estereotipos de género (National Academy of Sciences, National Academy of Engineering Institute of Medicine, 2007). 
En conclusión, a pesar de la mejora en la relación entre periodistas y científicos, la creciente relevancia de las mujeres en la ciencia queda ensombrecida, muchas veces de manera involuntaria, por los estereotipos y las representaciones sociales. Superar esta situación supondría su necesario reconocimiento para continuar fomentando las investigaciones realizadas por mujeres.

\section{Un análisis cualitativo: la representación social de las científicas en España.}

Como ya se ha expresado, en nuestra investigación hemos desarrollado tres grupos de discusión para desvelar las diferentes percepciones sociales de las mujeres científicas en España. A continuación, exponemos los resultados obtenidos, en su análisis cualitativo, ordenado en los siguientes epígrafes:

\subsection{Un desinterés manifiesto}

La encuesta realizada por la Fundación BBV en el año 2012, indica, como ya hemos mencionado, que el interés de la población española por la ciencia es de un 5,7 en una escala de cero a diez. Sin embargo, los participantes en los grupos de discusión ofrecen una opinión distinta, según sus declaraciones sobre la información científica publicada en los medios de comunicación. Para ellos, la presencia de la ciencia en los medios de comunicación es:

- Poquísima.

- Es muy poca.

- Es más de lo que la gente quiere.

- Tengo claro que le pones un programa de ciencia y no lo va a ver nadie.

- No interesa.

- La ciencia la tenemos tan lejana que ni nos preocupamos por ella.

- Yo (ingeniero) me considero en cierto modo científico y no consumo, no lo veo.

- Yo he puesto REDES alguna vez y no aguanto más de diez minutos.

- No echamos de menos más información científica...

El escaso interés de la población española por los temas científicos no depende de su nivel formativo. A los universitarios tampoco les interesa la información científica, prefieren otros contenidos, más livianos y triviales, de la programación actual de los medios. Entre sus preferencias destacan filmes y series, además de los espacios informativos de televisión. Los hombres se decantan por las retransmisiones deportivas, principalmente por el fútbol. El motivo de estas preferencias estriba en la necesidad de prestar una mayor atención y de realizar un mayor esfuerzo cognitivo, al exponerse a los mensajes científicos. Estos son algunos comentarios:

- Se recuerda la noticia científica no sus protagonistas.

- La información científica en los medios genera curiosidad en el receptor, pero...

- Pero te quedas con los otros porque no tienes que pensar. 
- Los programas de ciencia te hacen pensar.

- Estar concentrada, prestar más atención.

\subsection{Representaciones sociales distintas y conservadoras}

Las mujeres en España son percibidas, en general, como mujeres que trabajan fuera de su casa. Sin embargo, la imagen que tienen los hombres de las mujeres es muy distinta a aquella que tienen las mujeres de si mismas, y no se corresponde, en absoluto, con la realidad. Así se manifiesta en los siguientes comentarios extraídos del grupo de discusión masculino:

- Yo veo a la mujer, en el día de hoy, súper independiente y una igualdad total entre el hombre y la mujer. Todo el mundo ya en casa hace todo. No es como antiguamente que el hombre no sabía hacer nada y la mujer hacía todo. Y, de hecho, a día de hoy, vas conociendo chicas y no saben hacer ni un huevo frito. $\mathrm{Y}$ en los puestos de trabajo, se puede ver que el número de jefes es igual de hombres y mujeres y desempeñan las mismas funciones. Lo que tienen ellas es el tema de los embarazos, dar a luz, pero luego realmente cuando el bebé tiene unos meses ya es todo completamente igual. Y los hombres muchas veces: pues me tengo que ir antes porque tengo que recoger al niño del colegio. Eso antes era impensable.

- La mujer en España, muchas te dicen: nos han engañado, estamos haciendo lo que hacíamos antes y encima trabajamos.

- Pero eso no sólo en España.

- Yo creo que está cambiando mucho la cosa.

- Pero es cierto que tiene un papel de víctima.

Como acabamos de indicar, la imagen de las mujeres sobre sí mismas es muy distinta a la percibida por los hombres.

- Somos polifacéticas, llevamos muchísimas cosas a la vez, muchísimas.

- Lo que son responsabilidades, claro, y hacer cosas al a vez, lo típico que estás hablando por teléfono, cambiando al niño, y haciendo otra cosa, eso a un hombre no se lo puedes pedir.

- Yo creo que nosotras somos más perfeccionistas para todo.

Las mujeres se sienten obligadas a asumir más responsabilidades que los hombres en el ámbito del hogar y la familia; no se fían de los hombres a la hora de realizar estas tareas:

- Yo creo que mucha culpa la tenemos las mujeres... su marido le ha dicho "por qué lo tienes que hacer tú todo", como ir al médico porque el niño tiene 37,2 y ella decirle "no, porque me quedo más tranquila yendo yo". Como si el hombre no supiera hacer las cosas.

- La culpa es nuestra, sí.

- No digo que siempre sea así, pero es muy habitual...

- No somos iguales, uno puede ser mejor en ciertas cosas, hay hombres que cocinan mejor que mujeres, cada uno tiene su especialidad, como en todo, igual que hay profesiones que se nos dan a uno mejor que a otro... 
Lamentablemente, sigue sin existir un reparto equitativo y ponderado de las tareas del hogar:

- A la hora de trabajar los dos, cuando yo trabajaba todo el día, me levantaba hora y media antes, por tener ese tiempo para recoger la casa, porque luego llegábamos los dos de noche tardísimo y él no lo hacía porque no le daba la gana.

- Sí, pero no puedes todos los días levantarte con una bronca; a ver, poneros en la situación, dice: "se hace el sábado", "no, no, no se hace el sábado", entonces hay diferencia de opiniones... Él no le daba la misma importancia que le daba yo.

- Normalmente tenemos la conciencia de "él me ayuda"...

- Porque la educación de los niños, la gran responsabilidad recae mucho en las mujeres.

- Y hay madres muy machistas de nuestra generación.

- Porque se conforman, o se quedan en: ¡pero cómo lo va a hacer él!

La promoción profesional y la maternidad resultan incompatibles para las mujeres. La mujer que no quiere renunciar a ninguna de las dos cosas, precisa de una mayor flexibilidad horaria; pero, en cualquier caso, soporta, con un enorme esfuerzo, una duplicada jornada laboral.

- Y a nivel de trabajo, muchas mujeres cuando llegan a un nivel profesional intermedio deciden que no quieren seguir sacrificando más ¿sabes?, porque con lo que tiene ya le compensa, que nosotras mismas nos ponemos el veto porque nos vemos con otras cargas, y a un chico le da igual, y por eso siguen siendo vidas diferentes, pero también muchas veces por nuestra forma de pensar y porque nos han inculcado que tenemos que ser responsables de muchas más cosas...

- En España el poder ocupar un puesto directivo significa dedicarle muchas más horas al trabajo.

- Y muchas veces tienes que demostrar más...

- Lo que sí frena es a la hora de formar una familia, mi hermana tiene 34 años, la han ascendido, le encantaría ser madre, pero en este momento no se plantea porque no puede.

- Cuanto más joven eres vas teniendo una serie de ideales y a los 45 igual dices "mira, que se vayan los ideales por ahí, se acabó luchar contra las paredes".

- Se intenta conciliar, pero no se consigue al $100 \%$ y creo que eso va a pasar siempre.

- Si ves a alguna mujer en un puesto directivo va a ser difícil que... a lo mejor tiene hijos pero no los ve, tiene alguien que los cuide, entonces no ejercen como madres.

Ambas representaciones sociales de las mujeres, tanto la que mantienen los hombres, como la expresada por las mujeres, son, por distintos motivos, extremadamente conservadoras. Las de los hombres porque perciben como realidad una imagen estereotipada y victimista de las mujeres, en un entorno ficticio de igualdad entre 
géneros, fruto de un proceso de interiorización de ideologías, creencias y valores claramente machistas. Y las mujeres, porque, pese a considerarse responsables de la distribución no equitativa de las tareas familiares y del hogar, y responsables del proceso educativo de sus hijos, de acuerdo con esquemas y roles tradicionales, no están dispuestas a ceder parte de esas competencias a los hombres, al mismo tiempo que les reclaman sus mismos modos de pensamiento y conducta. No quieren que ellos hagan las cosas, quieren que las hagan como las harían ellas.

\subsection{La representación social de las personas de la ciencia en España}

Al hablar de las personas dedicadas a la ciencia, tanto mujeres como hombres, existe, en general, un alto consenso en su consideración.

- Con estudios universitarios.

- Inteligente sobre todo.

- Metódico.

- Con paciencia.

- Como de edad un pelín avanzado, más que gente joven, de más de 40 años.

- Los de 25 son becarios.

- Viven en ciudades grandes.

- Y extranjeros.

- No, pero hay fuga de cerebros.

- Esa carrera es bastante vocacional.

- Los veo como muy entregados, como" ratoncitos de laboratorio".

- Es un campo desconocido, hay un abanico, porque hay químicos, físicos, muy desconocido para mí, no conozco ni sus horarios, ni su trabajo, ni su día a día.

- Muy volcado en su trabajo.

- Tampoco conozco a nadie, pero supongo que tendrán horarios, como todo el mundo.

- No es una profesión corriente. No conocemos como funciona, es un campo muy desconocido.

Las mujeres asocian las tareas científicas con materias tales como la genética, las energías renovables, la biología, la química, la farmacia, la astronomía y la astrofísica, la ecología, la informática; también, con la historia, la arqueología, la arquitectura...

Los hombres, en cambio, vinculan el trabajo científico con los ámbitos de la medicina, la física, la ingeniería, la astronomía, la energía y otros. Sin embargo, dudan o niegan del carácter científico de las humanidades y de las ciencias sociales, como la filología o la historia.

\subsection{La representación social de las científicas en España}

$\mathrm{Al}$ relacional la variable género con la actividad científica, tanto los hombres como las mujeres asocian directamente la ciencia con la universidad. Así, pese al desconocimiento declarado de la actividad científica, no dudan en vincular a las mujeres y a 
los hombres con diferentes áreas científicas universitarias. Es una apreciación común de hombres y de mujeres:

- Sigue habiendo carreras que son tradicionalmente de hombres y de mujeres.

- Enfermería, farmacia tradicionalmente son de mujeres.

- Ingeniería menos.

- Coches, motores y eso no hay ni una mujer.

Los hombres, en general, perciben la presencia de más mujeres en todas las áreas científicas, a excepción de las ingenierías, en porcentajes muy superiores a los reales. Las mujeres, por su parte, consideran que, salvo en las áreas de salud, en las que habría más mujeres, y las ingenierías, dominadas por los hombres, la actividad científica tiene una distribución equitativa entre hombres y mujeres.

Tanto para hombres como para las mujeres, los puestos directivos en el ámbito de la ciencia, al igual que en el resto de las profesiones, están ocupados mayoritariamente por hombres, pero por diferentes razones y en desigual proporción. Las mujeres entienden que esta situación se produce por su imposibilidad de conciliar la vida laboral y la familiar.

- Claro, nunca vamos a poder tener acceso a ese tipo de puestos teniendo hijos. Va a ser muy difícil y en número mucho más reducido que los hombres, está claro.

- Y si se llega es sacrificando mucho, o sea, que quien ha llegado es que ha sacrificado mucho en lo personal.

Para los hombres, esta situación, es una cuestión de edad.

- Imagino que en edades más altas habrá muchos más hombres, de 40 para arriba.

- De 45 a 50 solo había hombres.

- A medida que se van jubilando se irán igualando.

\section{Conclusiones}

Exponemos, a continuación, las principales conclusiones, sobre la percepción social de las mujeres científicas, extraídas de las opiniones vertidas por los miembros de los grupos de discusión.

La profesión científica, según la opinión mayoritaria de los participantes, es una gran desconocida. Este desconocimiento llegaría a convertirse en total ignorancia si no fuera por la relación directa entre la ciencia y el mundo universitario y, en menor medida, por la difusión de los temas científicos en los medios de comunicación.

Queda claro que los contenidos científicos, difundidos por los medios de comunicación, no interesan, al exigir una mayor atención y un mayor esfuerzo en su comprensión, y por ello, no se recuerda ni el nombre, ni el género de sus protagonistas. 
La profesión científica es considerada una actividad muy vocacional, que precisa una gran exigencia de tiempo y dedicación, y se asocia generalmente con el trabajo de laboratorio.

Las mujeres científicas son percibidas como las demás mujeres profesionales, quizás con un mayor requerimiento de tiempo en su actividad.

En su trayectoria profesional, las mujeres científicas encuentran los mismos problemas, para el ascenso a cargos y funciones directivas, que en las demás profesiones.

Los miembros de los grupos consideran, que, en términos absolutos, existen más mujeres que hombres dedicadas a la ciencia, pero creen que las investigadoras son más jóvenes que los investigadores, y ocupan cargos de menor relevancia. Coinciden en afirmar que los jefes de los equipos y de los proyectos de investigación son hombres y de mayor edad.

Todos, mujeres y hombres, opinan que las mujeres están más vinculadas a los ámbitos de las ciencias de la salud, de las ciencias sociales y de las humanidades, y los hombres al campo de las ingenierías.

Si tenemos en cuenta que las humanidades y las ciencias sociales no son consideradas científicas por parte de los hombres, un gran número de mujeres quedarían desterradas del perímetro científico.

\section{Bibliografía}

CANDELA AGULLÓ, C., BARBERÁ HEREDIA, E. y RAMOS LÓPEZ, E. (2009): Perspectiva de género en el desarrollo de carrera: perfiles de competencias, logro de metas y dificultades encontradas, en Información Psicológica, $\mathrm{n}^{\circ}$ 97. http:// dialnet.unirioja.es/servlet/busquedadoc? $\mathrm{t}=$ estereotipos + genero $+\& \mathrm{db}=1 \& \mathrm{td}=-$ todo. (Consulta: 31-07-2013)

DURKHEIM, É. (2000): Sociología y filosofia. Miño y Dávila Editores, Madrid.

DOMINGUEZ-GUTIERREZ, S. (2006): Las representaciones sociales en los procesos de comunicación de la ciencia, en I Congreso Iberoamericano de Ciencia, Tecnología, Sociedad e Información CTS+I, México DF. http://www.oei.es/ memoriasctsi/mesa5/m05p21.pdf. (Consulta: 10-07-2013)

EUROPEAN COMMISSION (2012): She Figures 2012. Gender in Research and Innovation. Bruselas: European Commission.

GARCÍA NIETO, M. T. (2013): ¿Son invisibles las mujeres científicas?, en Estudios sobre el mensaje periodístico Vol. 19. 783-792.

HOGG, M. y VAUGHAN, G. (2010). Psicología Social. Madrid: Ed. Médica Panamericana. 
FUNDACIÓN ESPAÑOLA PARA LA CIENCIA Y LA TECNOLOGÍA (2008): Mujer y ciencia. La situación de las mujeres investigadoras en el sistema español de ciencia y tecnología. Madrid, FECYT.

FUNDACIÓN ESPAÑOLA PARA LA CIENCIA Y LA TECNOLOGÍA. FECYT (2011): Metacomunicación Cientifica y Periodismo Cientifico. Madrid: Ministerio de Ciencia e Innovación.

FUNDACIÓN ESPAÑOLA PARA LA CIENCIA Y LA TECNOLOGÍA. FECYT (2012): VI Encuesta de Percepción Social de la Ciencia 2012. Ministerial de Economía y Competitividad. Madrid

FUNDACIÓN BBV (2012): Estudio Internacional de Cultura Científica de la Fundación BBVA. Comprensión de la ciencia. Departamento de Estudios Sociales y Opinión Pública de la Fundación BBVA.

KHAN, Kim y GORDON, Ann (1997): How women campaign for the US Senate: substance and strategy, en Women, Media and Politics. Pippa Norris. London.

LACOLLA, L. (2005): Representaciones sociales: una manera de entender las ideas de nuestros alumnos, en Revista ieRed: Revista Electrónica de la Red de Investigación Educativa Vol.1, No.3 (Julio-Diciembre de 2005). http://revista.iered.org. (Consulta: 17-07-2013)

LIPPMANN, W. (1922): La opinión pública. Cuadernos de Langre. Langre.

MOSCOVICI, S. (1979): El Psicoanálisis, su imagen y su público, Buenos Aires, Ed. Huemul, $2^{\mathrm{a}}$ edición.

MOSCOVICI, S. (1984): The phenomenon of social representations, en Farr, F. y MOSCOVICI, S. (Ed.): Social representations, Cambridge University Press, Cambridge.

MUJERES Y CIENCIA. Fundación Telefónica. http://www.mujeryciencia.es/category/publicaciones/. (Consulta: 27-09-2013)

SEITER, Ellen (1986): Stereotypes and the Media: a Re-evaluation, en Journal of Communication, $\mathrm{n}^{\circ} 36$. Issue 2.

TORRES ALBERO, Cristóbal (2005): Representaciones sociales de la ciencia y la tecnología, en Reis, $\mathrm{n}^{\mathrm{o}} 111$. Disponible en http://dialnet.unirioja.es/servlet/articulo? codigo $=1380987$. (Consulta: 10-07-2013)

NATIONAL ACADEMY OF SCIENCES, NATIONAL ACADEMY OF ENGINEERING INSTITUTE OF MEDICINE (2006): Beyond Bias and Barriers: Fulfilling the Potential of Women in Academic Science and Engineering. National Academy Press. Washington.

UNIDAD MUJERES Y CIENCIA (UMYC) (2011): Libro Blanco. Situación de las Mujeres en la Ciencia Española. Madrid: Ministerio de Ciencia e Innovación. (Consulta: 10-09-2013)

UNIDAD MUJERES Y CIENCIA (UMYC) (2011): Cientificas en Cifras. Madrid: Ministerio de Ciencia e Innovación. (http://www.idi.mineco.gob.es/portal/ site/MICINN/menuitem.7eeac5cd345b4f34f09dfd1001432ea0/?vgnextoid=e218c5aa16493210VgnVCM1000001d04140aRCRD. (Consulta: 10-09-2013) 


\section{Las autoras}

María Teresa García Nieto es Profesora Titular de Universidad en la Universidad Complutense de Madrid, doctora en Publicidad y Relaciones Públicas, licenciada en Ciencias de la Información y en Ciencias Políticas y Sociología, posee los estudios del Doctorado en Psicología, y es Master en Comunicación Corporativa y Publicitaria. Es la directora del Proyecto de investigación IFIGIC y presidenta del Centro de Estudios de Estrategias de la Comunicación.

Mónica Viñarás Abad es Doctora en Ciencias de la Información por la Universidad Complutense de Madrid y Profesora Adjunta en la Universidad CEU San Pablo. Forma parte de distintos proyectos de investigación y es miembro de asociaciones profesionales como Icono 14, ASOCREA, AIRP y AE-IC. Sus líneas de investigación son las Relaciones Públicas y la imagen corporativa. 